\title{
FRÍGIDOS Y MALEFICIADOS. LAS MUJERES Y LOS REMEDIOS CONTRA LA IMPOTENCIA EN LA EDAD MEDIA ${ }^{1}$
}

\author{
Paloma Moral de Calatrava
}

Universidad de Murcia

\section{RESUMEN}

En la Edad Media las causas y origen de la impotencia masculina no sólo se atribuyó a diversas causas naturales, sino que también al poder de la brujería. Los médicos podían utilizar recetas antiguas, pero también recogieron remedios que fueron conocidos y utilizados por las mujeres. De modo que el mismo remedio era aceptable cuando lo respaldaba la medicina académica o se consideraba hechicería si lo utilizaban las viejas sabias (vetulae). Este trabajo explora los conocimientos de las mujeres sobre los tratamientos disponibles y su papel como sanadoras del cuerpo y la masculinidad de los hombres.

PALABRAS CLAVE: Impotencia. Mujeres. Masculinidad. Brujas. Coito. Satirión.

\section{FRIGID AND BEWITCHED: WOMEN AND REMEDIES AGAINST IMPO- TENCE IN THE MIDDLE AGES}

\begin{abstract}
During the Middle Ages, the causes and origin of male impotence were attributed not only to various natural causes but also to the power of witchcraft. Physicians could refer to treatments prescribed in the traditional medical canon but could also use remedies that were known to, and used by, women. As a result, the same cure could, in effect, be sanctioned when detailed by a male physicians but be condemned as witchcraft if it were to be prescribed by a female (vetulae). This study considers the knowledge that women had concerning available treatments for impotence, and their role in restoring feelings of male empowerment and masculinity.
\end{abstract}

KEY WORDS: Impotence. Women. Masculinity. Witches. Intercourse. Satirion.

1 Este trabajo se enmarca en el proyecto 08827/PHCS/08 de la Fundación Séneca. Agradezco a Montserrat Cabré sus comentarios y sugerencias. 
«En la ciudad de Ratisbona, un joven mantenía relaciones con una muchacha. Cuando quiso abandonarla, perdió su miembro viril bajo los efectos de algún sortilegio hasta el punto de no tocar ni ver más que una superficie aplastada. Angustiado por ello, se fue a una taberna para adquirir vino. Sentándose un momento, se puso a hablar con una mujer para contarle con detalle la causa de su tristeza, mostrándole lo que ocurría en su cuerpo. Astuta, ella le preguntó si sospechaba de alguna mujer. Él le dijo que sí y le dio el nombre de ella, contándole, además, lo que le había pasado. La mujer le dijo entonces: si para decidirla a devolverte la salud no es bastante utilizar buenos modales, convendrá usar de alguna violencia. Así, el joven, al llegar el crepúsculo, se apostó en el camino por el que habitualmente pasaba la bruja. Cuando la vio le rogó que devolviese la salud a su cuerpo. Ella se declaró inocente y afirmó que no sabía nada del asunto. Entonces, arrojándose sobre ésta, le rodeó el cuello con una toalla ahogándola, mientras le decía: si no me devuelves la salud, morirás a mis manos. Como no podía gritar, ya tenía la cara tumefacta y se ennegrecía. Líbrame, dijo, y te curaré. El joven aflojó el nudo y la presión. La bruja le tocó entonces entre las piernas y le dijo: ya tienes lo que deseas. Como el joven contaba después, él había sentido perfectamente, antes mismo de asegurarse por medio de la vista y el tacto, que su miembro le había sido devuelto sólo por el tocamiento de la bruja» (Krämer,2004, p. 206).

En este pasaje del más célebre manual de inquisidores, el Malleus maleficarum de Krämer y Sprenger (1486), se acusa a las brujas de ser capaces de provocar la impotencia de los hombres hasta el punto de crear la falsa ilusión maléfica (prestigium) de que los habían privado de su pene (Kieckhefer, 1976, p. 61; Broedel, 2003, p. 27). Durante la Edad Media se creyó que las brujas coleccionaban sus miembros en árboles, creencia que está ilustrada en las pinturas murales de Massa Maritima (hacia 1265), en donde unas mujeres custodian unos veinticinco penes que, a modo de pájaros en sus nidos, cuelgan de un gran árbol (Ferzoco, 2004; Longenbach, 2008; Smith,2009). Tres siglos después, en The Discoverie of Witchcraft (1584), Reginald Scot recogió esta creencia legitimada bajo la autoridad del Malleus (Scot, 1651, pp. 60-1), de modo que a finales del siglo XVI la asociación de la brujería con la impotencia era un tópico tan extendido que el propio Shakespeare alude a ello en Las alegres comadres de Windsor (Krämer, 2004, pp. 265-6; Cotton, 1987).

La responsabilidad femenina sobre la impotencia masculina había sido ya frecuentemente aducido en todo tipo de documentos medievales, entre ellos tratados médicos y textos de derecho canónico. Estas obras, escritas por hombres, al admitir que las mujeres eran capaces de restituir el pene robado estaban reconociendo implícitamente que eran depositarias de unos saberes que podían remediar tan vergonzoso mal. El recelo a reconocer la competencia femenina sobre los saberes médicos se consolidó con su exclusión de la for- 
mación universitaria, de modo que la constatación de que eventualmente podían curar la impotencia sólo podía vincularse a que ellas mismas la habían causado por medio de hechicerías (Stephens, 1998, p. 499 y 511; Stephens, 2003, pp.318-21; Smith, 2002). La teoría galénica permitía explicar la etiología de la impotencia basándose únicamente en causas naturales, pero los médicos aceptaron causas mágicas entre los desencadenantes de esta disfunción. Así pues, en la Edad Media fue común la presunción de que las mujeres sabían cómo provocar impotencia a los hombres. Este problema no era sólo un asunto médico, sino que también tuvo implicaciones legales y religiosas; porque si un hombre era incapaz de consumar su matrimonio éste podía deshacerse, de ahí que los tribunales eclesiásticos y, por ende, los médicos, tuvieran que enfrentarse al reto de identificar la causa que provocaba la falta de potencia sexual, establecer su duración y determinar el momento de inicio. La impotencia podía ser natural o mágica, de modo que el elenco de soluciones disponibles iba desde los fármacos naturales a los remedios mágicos, sin desdeñar los métodos presuntamente curativos prescritos por la Iglesia, sobre todo la oración y la penitencia.

La historiografía reciente ha puesto en valor la función de las mujeres como proveedoras de cuidados de salud, especialmente hacia otras mujeres (Green, 2008; Cabré, 2005; Cabré, 2008, Caballero, 2008a; Caballero, 2008b), pero en este trabajo destacaré, a través del caso de la impotencia, que los tratamientos que aparecen en los tratados médicos eruditos fueron los mismos que se recopilaron en los manuales de medicina práctica y los que utilizaron las mujeres para curar al hombre impotente. Pensar que gran parte de la sociedad utilizaba remedios provenientes de la cultura popular y que los medicamentos del saber ilustrado fueron accesibles sólo para unos pocos, es una asunción que poco tuvo que ver con las estrategias que se emplearon para afrontar la curación, y la impotencia masculina no fue una excepción. Aunque en la práctica era frecuente el recurso a las viejas mujeres sabias (vetulae) para solucionar la impotencia, en teoría los médicos sólo aceptaban como válidos los remedios propuestos por la medicina académica y la «medicina eclesiástica», es decir, los rituales contra la enfermedad aprobados por la Iglesia (Kieckhefer, 1994, p. 833). En este artículo mostraré cómo los médicos utilizaron con frecuencia las mismas terapias contra la impotencia que cuando eran usadas por las mujeres se consideraban materia de hechicería (Rider, 2011, p. 98). Es decir, los médicos académicos, los prácticos y las mujeres intercambiaron remedios, pero estos hombres no estuvieron dispuestos a reconocer a las mujeres más competencia sobre el cuerpo masculino que aquella que las relacionaba con la enfermedad y el pecado, atribuyéndoles la responsabilidad de la impotencia masculina. Los co- 
nocimientos de estas mujeres nunca fueron admitidos porque los hombres nunca lo permitieron, sabedores de la importancia simbólica de esta competencia femenina sobre la potencia sexual en la que radicaba la masculinidad.

\section{LA IMPOTENCIA: UNA MAGIA DE MUJERES.}

En la Francia del siglo IX, cuando todavía no existía una liturgia matrimonial estable, Hincmaro de Reims escribió por primera vez sobre la impotencia mágica en su tratado De divortio Lotharii et Tetbergae al describir el siguiente caso que había vivido su predecesor en la archidiócesis. Un joven se enamoró de una muchacha y la pidió oficialmente a sus padres. A pesar de la negativa de la madre, el padre accedió y se celebró la boda. Sin embargo, el marido no fue capaz de consumar el matrimonio durante dos años, y acudió al obispo solicitando su anulación. Pero éste, «a quien ya se le habían presentado otros casos semejantes, que con frecuencia suceden por obra de Satanás..., razonando y discutiendo, al fin, con la gracia de Dios, logró disipar las maquinaciones diabólicas, de suerte que lo que antes le era posible con la amante y no con la esposa legítima, con penitencia adecuada y gracias a la medicina de la Iglesia, el joven finalmente lo logró también con su mujer.» (Migne 125: $717 \mathrm{a}-717 \mathrm{c}$ ). Hincmaro concluyó que el matrimonio era válido porque finalmente había sido consumado (Heidecker , 2010, pp. 92-99), pero poco después se le presentó el caso de Esteban, un conde de Aquitania que se había prometido con la hija de otro noble de la región. Poco después de la boda, Esteban había compartido lecho con una familiar de la novia. Conseguía así sembrar una duda razonable: ¿estaba casado con la hija del conde Raymond o con la mujer con la que había copulado previamente? Hincmaro consideró que Esteban debía estar hechizado cuando fue atraído al lecho de otra mujer, no obstante el matrimonio no consumado era incompleto y por lo tanto disoluble. Se planteaba así el gran problema del coito en la formación de un matrimonio cristiano (Reynolds, 1994, pp. 353-361; Murray, 1998, pp. 132-3 y 147). Este caso le dio la oportunidad de introducir uno de los párrafos más significativos en su De nuptiis Stephani et Filiae Regimundi Comitis: el conocido Si per sortiarias...:

«Si por causa de hechiceras y magas, con permiso del juicio de Dios —oculto, pero nunca y en ningún lugar injusto - y mediante los manejos del Diablo, sucede [que una pareja no pueda mantener relaciones sexuales], se debe animar a que la pareja haga una confesión pura de todos sus pecados ante Dios, con un sacerdote 
de corazón contrito y espíritu humilde. Con muchas lágrimas y muy generosas limosnas, oraciones y ayunos, deben satisfacer al Señor (...). Los ministros de la Iglesia deben ocuparse de su sanación en la medida que Dios — quien sanó a Abimélec y su casa por las oraciones de Abrahán- lo conceda, a través del exorcismo y otras medicinas eclesiásticas. Aquellos quienes por cualquier causa no puedan ser curados, pueden ser separados; pero después de que hayan buscado otros matrimonios, mientras aquellos con quien estén casados permanezcan vivos, no pueden ser reconciliados con sus antiguos compañeros a quienes han abandonado, incluso si la capacidad de mantener relaciones sexuales ha vuelto a ellos» (Migne, 126: 151a-151d).

Para Hincmaro, Satanás podía transformar en una pareja el amor en odio y viceversa, y pone como ejemplo el caso del senador cristiano Porterio, que quiso consagrar a su hija a la vida monástica y ofrecer así un sacrificio a Dios. Pero uno de los siervos del senador fue tentado por el Diablo, que le forzó a renunciar por escrito a la religión cristiana para conseguir que ella se enamorara del siervo (Giordano, 1983, pp. 294-5). La impotencia, como el amor, podía tener un origen mágico, e Hincmaro la consideró como un problema de salud que podía resolverse con «medicina eclesiástica» (Payer, 2009, p. 23). Confesión, oración, ayuno, penitencia e incluso exorcismo, fueron los tratamientos apropiados para un problema de causa sobrenatural conocido desde antiguo (Faraone, 1999). Los conceptos de impotencia y amor mágicos de Hincmaro perduraron en la colección canónica que Burcardo de Worms compiló en 1020, que contenía una parte penitencial conocida como Corrector sive medicus (Austin, 2009). Las mujeres eran las protagonistas de este proceso; ellas podían provocar que el hombre se volviera impotente con la mujer con la que se había casado, o bien transformar el amor que sentía hacia su esposa en odio, y por eso pregunta: «¿Has creído o participado en la superstición según la cual hay mujeres capaces de mudar los sentimientos de los hombres por medio de maleficios y de encantamientos, cambiando el odio en amor y el amor en odio, o que con el mal de ojo pueden arrasar o destruir los bienes de los hombres? Si has creído o participado en tales actos, debes cumplir pena durante un año en los días festivos señalados (...) ¿Has hecho lo que algunas mujeres adúlteras acostumbran a hacer? Cuando saben que sus amantes quieren tomar una esposa legítima, extinguen el deseo de los hombres por algún medio mágico para que sean impotentes y no puedan consumar la unión con la esposa legítima. Si lo has hecho, o enseñado a otros cómo hacerlo, debes cumplir pena durante cuarenta días a pan y agua» (Gagnon, 2010; pp. 122 y 149).

Durante la Edad Media los agentes, las causas y los medios que se empleaban para provocar impotencia mágica se resumían en un grupo social: las 
mujeres despechadas. Los casos recogidos en fuentes de distintos siglos muestran, además, un deseo de hacer presentes los hechos aunque sean historias remotas. Por ejemplo, si Tomás de Chobham en su Summa confesorum de 1217 cuenta que en París una mujer impidió por un hechizo que su antiguo amante pudiera mantener relaciones con su esposa hasta que recogieron una cerradura y la llave que había tirado a pozos distintos (Rider, 2006, pp. 97-8), el Malleus maleficarum relata prácticamente el mismo procedimiento e idéntica causa en el caso de un joven noble de la diócesis de Estrasburgo, así que «vuelto a su casa el conde no tardó en mandar vaciar el pozo, encontró la marmita, y quemando lo que contenía súbitamente recuperó la potencia viril perdida. Por ello la condesa invitó a la nobleza a unas nuevas bodas, diciendo que ella era entonces señora de su castillo y de su condado después de haber permanecido virgen durante tanto tiempo» (Krämer, 2004, p. 219). La ausencia de contacto sexual tras la boda provocó que esta pareja tuviera que celebrarla de nuevo, pues los cónyuges no estaban completamente amparados por el sacramento del matrimonio (Stephens, 2003, pp. 315-21). Algunas mujeres, calificadas como brujas, fueron consideradas causantes de la impotencia masculina y capaces, incluso, de anular la eficacia del sacramento matrimonial. Aunque contaban con una amplia variedad de procedimientos, la ligadura fue uno de los más empleados (Cohn, 1980, p. 252). Dentro de la iglesia, y cuando el sacerdote decía «Lo que Dios ha unido, que no lo separe el hombre» estas mujeres respondían «pero deja que el Demonio lo haga (...) lanzando una moneda sobre su hombro y haciendo un nudo en un hilo» (Jennett, 1963, p. 172). El miedo a este problema era evitado mediante matrimonios secretos, de modo que bien celebraban la boda en la iglesia de otro pueblo, o los contrayentes mantenían relaciones sexuales antes de la ceremonia religiosa, invirtiendo así el procedimiento canónico (Murray, 1998, pp. 139-41).

Pero en lo que se refiere a los médicos, no siempre atribuyeron a las mujeres la culpa de la impotencia. Por ejemplo, Constantino el Africano identificó diversas pociones confeccionadas para provocar impotencia masculina, pero no menciona que su elaboración fuera cosa de mujeres (Green, 1994, pp.1401). Sin embargo, desde que Tomás de Aquino sostuviera que el Diablo era capaz de impedir la formación de un matrimonio interfiriendo en la potencia sexual del varón (Aquino, 1961, p. 618), teólogos y médicos estuvieron de acuerdo en identificar progresivamente a las mujeres como las causantes de este mal (Jones y Zell, 2005). No obstante, ofrecieron soluciones diversas; para los primeros la peregrinación, la confesión, la señal de la cruz, la oración y el exorcismo, constituyeron remedios convenientes para la curación de la impotencia; en suma, la «medicina eclesiástica» propuesta en el IX por 
Hincmaro fue consagrada en el Malleus maleficarum (Krämer, 2004, p. 363). Los médicos, sin embargo, ofrecieron tratamientos complementarios que aparecían tanto en libros de magia como en reputadas obras médicas, situándose así en muchas ocasiones en el tenue límite que desde el siglo XIII separaba la filosofía natural de la magia natural.

\section{LA MEDICINA Y LOS REMEDIOS PARA LA IMPOTENCIA.}

La impotencia podía tener una etiología natural o mágica, y los tratamientos debían ser consecuentes con su naturaleza. Mientras que para la primera era necesario que los médicos establecieran si era un impedimento permanente para que el hombre contrajera matrimonio, la mágica solía afectar a la potencia del miembro viril sólo si trataba de mantener relaciones sexuales con la esposa legítima. Esta situación colocaba a los médicos en una posición difícil: de una parte debían determinar su causa y, por otro lado, establecer las probabilidades de curación. La impotencia mágica obligaba a reconocer, como hizo Juan de Aviñón en 1384 que «las cosas que son en Dios non pueden ser corregidas por Física» (Aviñón, 1885, p. 277), y «puesto que estos maleficios, producidos sobre todo por las mujeres, son diabólicos, a veces los curan los humanos y otras se remedian gracias al auxilio divino» (Sigerist, 1943, p. 542). Aunque el coito formaba parte de las seis cosas no naturales necesarias para conservar la salud (García Ballester, 1993), los médicos se plegaron al punto de vista de los teólogos y estudiaron los problemas de erección considerando que la reproducción era la única finalidad de las relaciones sexuales. Para la medicina académica la impotencia masculina era consecuencia de la complexión testicular, y de la falta de humedad, ventosidad y calor que generaban cerebro, corazón e hígado respectivamente (Burnett, 1994, pp. 99-120). De acuerdo con Gordonio, la medicina podía diagnosticar a los hombres de tres problemas: gonorrea, satiriasis e impotencia, término que se englobó y ocultó en el polisémico concepto de esterilidad (Gordonio, 1993, p. 1406). Siguiendo el principio de humedad, ventosidad y calor, el médico recomendaba una dieta que restaurara la complexión del afectado, y para ello elegía alimentos que poseían estas tres cualidades, como habas y garbanzos, u otros que al menos tuvieran dos de ellas y pudieran ser condimentados con especias como jengibre o pimienta (Tractatus, 1993, pp. 142-149).

Pero junto a éstos, hubo otros alimentos que por sus propiedades ocultas fueron muy apreciados, como los testículos, la verga o el útero de animales como el toro, el ciervo, la liebre o el zorro (Page, 2000, pp. 63-64). Sin em- 
bargo, no todas las partes de animales que aparecen en las recetas para estimular el coito fueron tales. Ibn al-Jazzār, en su libro Zād al-musāfir, sigue a Dioscórides al recomendar los «testículos de zorro» (Ibn al-Jazzār, 1997, pp. 243-4), y este ingrediente se mantuvo en los más prestigiosos manuales de medicina durante toda la Edad Media. Pero, en un principio, no fueron la parte anatómica de un animal, sino, como aclaró Constantino, una planta llamada «satirión» (Constantino, 1983, pp. 150-1). El parecido de la raíz de esta orquídea con los testículos del animal le confirió desde antiguo su nombre y permitió que se le atribuyera valor afrodisíaco (Metrodora, 1953, p. 53 y 114; Aecio, 1950, p. 43; Stannard, 1982, pp. 14-5; Stannard, 1964, pp. 361-2). Aunque no siempre ambos términos fueron entendidos como una sola planta, porque mientras que en el De vegetabilibus Alberto Magno identificó al satirion y al testiculus vulpis como la misma hierba (Stannard, 1979, p. 311 y 314), en el Canon de Avicena sólo aparecen sus propiedades terapéuticas sin aclarar que se trata de partes concretas de una orquídea (Avicena, 1507, pp. 157 y 159). Así que en el siglo XIII se recogieron ambos términos, pero ello no significa que la información fuera accesible a todos los médicos. Por ejemplo, aparecen como dos sustancias distintas en una receta para hacer crecer el esperma en la traducción que Arnaldo de Villanova hizo del Kitab aladwiya al-mufrada de Abu-1-Salt (Translatio, 2004, p. 349), pero cuando esta traducción latina se vertió al catalán (XIV) los testículos de zorro habían desaparecido de la receta (Libre D'Albumesar, 2004, p. 541; McVaugh, y Ferre, 2000, pp. 102-4).

La confusión, incluso en círculos académicos, entre la raíz de la orquídea y las gónadas del animal es comprensible si tenemos en cuenta que se emplearon genitales de otros muchos animales para favorecer el coito. La Espistula vulturis es un buen ejemplo del modo en el que se produjo la introducción, confusión y aceptación de remedios de magia simpática en libros de medicina. Al final de una copia del año 800 del primer libro de la Materia medica de Dioscórides aparecen diecisiete recetas mágicas elaboradas con distintas partes del buitre, y la décimoprimera recomienda ingerir con vino sus riñones y testículos para quien no pueda yacer con su esposa, de modo que estos remedios, finalmente, estuvieron respaldados por grandes médicos (Horden, 2011, pp. 7-9; Mackinney, 1943, pp. 494-496). Gordonio reconoció las propiedades afrodisíacas de muchas partes de animales y también incluyó el satirión y los testículos del zorro. Como Arnaldo, no parece que tuviera claro que estos dos compuestos fueran la misma planta, y por ello recoge una receta tan potente que recomienda que sólo sea revelada a los hijos, en la que mezcla satirión con testículos de gallo y zorro (Gordonio, 1993, p. 1415). La confusión per- 
sistió durante toda la Edad Media y no se resolvió, al menos, hasta el siglo XVI. Así se refirió Andrés Laguna a este problema cuando comentó la Materia medica de Dioscórides:

«Usurpan oy casi todos los Medicos en lugar del Satyrion, las especies del Compañon del Perro, llamado Cynosorchis en Griego; porque si bien miramos, à cada una de las diferencias que del Satyrion ordinariamente muestran los Herbolarios, tiene dos, ò tres como compañoncicos de Perro, todos juntos, y asidos en una misma raiz; los quales no atribuyó jamàs el Satyrios Dioscorides, sino una sola raiz como una manzana. Dado que algunos Barbaros le deseriven de otra manera: de suerte que no consta entre los hombres doctos, qual planta sea el verdadero Satyrion» (Laguna, 1733, p. 132).

Aunque los médicos no abandonaron la idea de explicar la impotencia y tratarla de acuerdo a la teoría humoral, al aceptar que existían causas que estaban fuera de la naturaleza terminaron por asumir remedios empíricos (Montero, 2010, p.134). Por ejemplo, Constantino el Africano en el Liber de coitu limitó el tratamiento al juego sexual previo al coito, propuso distintas recetas que seguían el principio «contraria contrariis curantur» y recogió algunos remedios que aseguró que habían sido experimentados (Constantino, 1983, pp. 158-185), pero en la versión latina que hizo del libro de al-Majusi, conocido como Pantegni, incluyó un capítulo sobre la impotencia mágica (Green, 2005a, pp.145-147). La recepción del aristotelismo a partir del siglo XIII en las universidades europeas potenció una tendencia racional en medicina, pero la idea de que poderes maléficos actuaban sobre el cuerpo provocando enfermedades no pudo desterrarse. Gordonio en su Lilium medicinae trató la impotencia masculina como un problema derivado, básicamente, de causas naturales, de las cuales la principal es una complexión fría, pero reconoció que había casos en los que no se podía restaurar la salud corporal y, teniendo en mente el encabezamiento de un capítulo de las Decretales de Gregorio IX, afirmó que «este capitulo se puede intitular delos enfriados e maleficiados e enfechizados» (Gordonio, 1993, p. 1407). A pesar de que el montepulsiano admitió que las mujeres eran la principal causa del mal y que un maleficio podía causar impotencia, sólo tomó en consideración causas médicas, como un desordenado estilo de vida, desequilibrios en la complexión del afectado y algunas enfermedades de otros órganos, por lo que limitó el tratamiento a reconducir los hábitos del enfermo, a restablecer su complexión o a curar las enfermedades que la provocaban (Gordonio, 1993, pp. 207, 1411-1417; Demaitre, 1980, pp. 26-27 y 86-7 y 157-162).

Sin embargo, estas explicaciones racionales no fueron tendencia general en la Edad Media (Macdougall, 2000, pp. 264-265; Olsan, 2003, pp. 352- 
354). La circulación de obras menores de marcado carácter práctico constituyó una fuente de información principal para médicos no universitarios: cirujanos y barberos. Estos textos se caracterizan por utilizar tratamientos que aparecían en libros universitarios desprendiéndose de sus fundamentos teóri$\cos \mathrm{y}$, de otra parte, recopilar remedios que fueron conocidos y utilizados por las mujeres. Este es el caso del Tractatus de sterilitate, un texto anónimo del siglo XIV basado en el Lilium de Gordonio y dirigido a médicos prácticos. En él se asocia la impotencia con una complexión patológica, ya sea demasiado fría o cálida, o con un hechizo, cuya curación «hay que confiar a Dios mediante su eliminación o interrupción por obra de los propios autores del maleficio, aunque algunos tratados médicos expongan algunos remedios empíricos, como, por ejemplo, llevar colgado al cuello azogue en una cáscara de avellana o colgar artemisa en el dintel de la casa donde yacen marido y mujer» (Tractatus, 1993, p. 127). En este tratado, como en muchos otros de la Edad Media, el autor es un médico anónimo que sigue a una autoridad, pero se siente con la libertad suficiente como para incluir remedios provenientes bien de su propia experiencia bien de la de otros, aunque, como es usual, no siempre cita a sus fuentes (Montero, 1999, p. 714).

Los tratamientos que aparecían en los textos prácticos eliminaban la teoría que los sustentaba, y estos remedios eran atribuidos a médicos célebres como medio para justificar su inserción. De hecho, en la medicina práctica cambiar la autoridad que avala una receta o incluir fórmulas empíricas como tratamientos respaldados por nombres de médicos preeminentes será una práctica habitual. Esta forma de proceder se aplicaba también a las traducciones vernáculas, y éste es el caso de lo que hasta ahora se ha considerado la versión castellana del Compendium medicinae de Gilbertus Anglicus, de 1471. Este manuscrito español, sin embargo, no parece ser una versión del libro que el inglés redactó entre 1230 y 1240 (Green, 2005b, p. 196). De hecho, un análisis detallado me lleva a pensar que, por sus similitudes en estructura y contenido, es una traducción del Thesaurus pauperum de Pedro Hispano (Hispano, 1973, pp. 40-1). La versión castellana, aunque respeta su contenido, divide en dos el capítulo Ad coitum excitandum del Thesaurus: el XLIII, «de los que non son poderosos para dormir con muger» en el que el paciente ya está diagnosticado de impotencia, y el XLIIII, «sy quisieres ser guardado tu e la tu casa de los malefiçios del demonio o quisieres sanar si te han fecho algunos malefiçios», donde recoge una amplia variedad de amuletos y formas de evitar y eliminar maleficios, entre los que se encuentran la cáscara de avellana rellena de azogue y la práctica de colgar artemisa en el dintel de la puerta. Pero en lugar de considerarlos remedios empíricos, como hicieron el propio 
Pedro Hispano o el autor del Tractatus de sterilitate, atribuye la primera a Constantino y la segunda a Dioscórides.

«iten dize costantinus toma vna pluma o vna avellana vazia et jnchele la de azogue et ponla de yuso del çervigal quando dormjere o en el vnblar de la puerta por entre sanara del maleficio (...) iten dize diascorus que el que toxiere consigo la yerva que es dicha artemjsa et la rrayz' de la bretonjca sera defendido de todo malefiçio et la casa donde estas yerba estovieren colgadas en el vnblar de la puerta» (Libro de recetas, 1997, fol. 33v).

Como veremos, la medicina académica terminó por acoger tratamientos que aparecían en los textos prácticos atribuyéndoselos a grandes médicos, y fueron remedios que las mujeres utilizaron para devolver a los hombres su potencia sexual. Pero las fuentes escritas que muestran el uso femenino de medicamentos para la impotencia masculina asocian a estas mujeres a contextos que se situaban al margen de lo social y moralmente aceptable.

\section{LAS MUJERES Y EL USO DE LOS MEDICAMENTOS PARA LA IMPOTENCIA.}

Los remedios que utilizaron las mujeres pudieron convertirse en tratamientos académicos respaldados por profesores universitarios que se recopilaron, utilizaron y transmitieron en distintas lenguas (Riddle, 2010). El emplasto a base de hormigas muestra cómo la misma receta, que fue en origen un recurso mágico, terminó por estar avalada por las autoridades médicas. El Libro de los olios, un manuscrito castellano de finales del XV atribuido al profesor de medicina en Salamanca Gómez García (Amasuno, 1991, p. 106; García Ballester, 2002, p. 714), adscribe este remedio a Hipócrates, mientras que el Libro de amor de las mujeres, un compendio judío de mediados del XIII que, según Caballero Navas, contiene un abanico de conocimientos de origen femenino ya había recogido esta misma receta sin atribución alguna. Así lo expresa este tratado judío:

«Para fortalecer el coito y copular bien, con ardor: toma la cantidad de cuatro onzas de hormigas grandes que tienen alas y deposítalas en un recipiente de cristal claro y limpio. Después, añade unas ocho onzas de [...]. Cierra la vasija inmediatamente y ponla al sol y, cuando mueran las hormigas agrega cinco onzas de aceite de musco o aceite de castor. Manténlo treinta días al sol en verano, y en invierno hierve el recipiente en una olla llena de agua hasta que mengüe la cuarta parte. 
Después de esto, unta el resultado sobre los riñones, o aplica al miembro viril y obrará grandes prodigios» (El libro de amor, 2003, p. 42 y 32).

La formulación del profesor salmantino, sin embargo, es más simple:

«Olio de formigas segun Ypocras. Es prouechoso para esforçar el omne et la mugier al coyto si fuere vntado conel la renes et el pendejo et el berretro ${ }^{2}$. E fazese desta gujsa. Toma formjgas biuas, mjll o mas et echalas en azeyte en vn vaso tanto quanto esten cubiertas, et bien tapado el vaso de vidrio. E si fueren de las formjgas que buelan seran meiores, o de las formigas montesinas que son medio rubeas, et medio negras. E esten al sol quarenta dias, despues cuelalo, o sin colar guardalo» (Gómez, 1997, fol. 14r.)

El mismo remedio, que se utilizó tanto en el XIII como en el XV, fue conocido por judíos y cristianos, y utilizado tanto por mujeres como por hombres. Las diferencias entre ambas, sin embargo, son importantes. Si la receta judía, más antigua, aparece en una parte del texto de marcado carácter mágico sin autoridad que la avale, en el castellano está respaldada por el mismísimo Hipócrates. Tal y como fue redactada en este último pudiera dar la impresión de que el emplasto podía ser eficaz para hombres y mujeres, pero, al menos desde San Isidoro, la libido masculina se situaba en los riñones, mientras que la de las mujeres estaba en el ombligo, por lo que debe ser entendido como un medicamento específico para los hombres (Isidoro, 1982, p. 98; Jacquart, 1987, p. 9). Además, esta receta es de origen salernitano, ya que fue Constantino quien la introdujo en su Liber de coitu como remedio empírico (Constantino, 1983, p. 183). De modo que es un ungüento que desde un principio estuvo diseñado para la estimulación del apetito sexual masculino que demuestra que entre la medicina académica y la práctica hubo constantes intercambios de fórmulas para curar la impotencia, y que su uso no se quedó en la élite intelectual, sino que llegó a ser conocida y aplicada por las mujeres.

Lo que los textos muestran es un proceso, concordante con la exclusión de las mujeres del medio universitario, de cancelación de los saberes y la práctica femenina (Moral, 2010), aunque ellas utilizaran los mismos remedios que serían recogidos en tratados médicos de importante difusión e influencia en la Edad Media. Colgarse al cuello el diente de un hombre muerto o hacerse una fumigación con él es un buen ejemplo de ello. En el Libro de amor de las mujeres, dentro de un contexto mágico, simplemente se recomienda «para quien no puede yacer con su mujer por cualquier razón, esto ha sido probado:

\footnotetext{
2 «Berretro» o «veretro» significa «órganos sexuales» (Herrera, 1996).
} 
toma un diente de hombre muerto y que se lo cuelgue al cuello; inmediatamente hará lo que desee; o que haga sahumerio con el [diente]» (El libro de amor, 2003, pp. 41-1). El mismo remedio aparece en el Thesaurus pauperum, y de nuevo el aval de la autoridad médica es un elemento esencial. Si en el texto hebreo está respaldado únicamente por la experiencia, Pedro Hispano se lo atribuye a Gilbertus Anglicus (Hispano, 1973, p. 237; Gilbertus, 1510, fol. 287r; Forbes, 1971, p. 308), mientras que la versión castellana de esta misma obra - que, recordemos, está erróneamente atribuida al inglés - lo adscribe a Quirinus (Libro de recetas, 1997, fol. 33v). Las propiedades de los dientes de hombre muerto contra la impotencia no fueron conocidas únicamente por los iniciados en las artes de la magia o la medicina, pero las mujeres que los utilizaban fueron asociadas con la brujería. Fernando de Rojas, que conoció al médico López de Villalobos (Moral, 2007), construyó en el personaje de la Celestina el estereotipo literario de la mujer sabia y bruja del fin de la Edad Media castellana (Dangler, 2001; Harper, 2011). El objetivo principal de la alcahueta es provocar el amor mágico de Melibea, sin embargo el camino se antoja lleno de dificultades. Una de ellas es la objeción que hace uno de los criados de Calisto, Pármeno, que conoce a Celestina desde que era niño. Para advertir a su señor de los peligros de entrar en contacto con esta mujer, describe sus seis oficios: lavandera, perfumera, hacedora de afeites y de virgos, alcahueta y, finalmente, hechicera. Al menos dos de estos oficios están relacionados con la actividad sexual: como alcahueta su trabajo consiste en favorecer el encuentro carnal y que las mujeres pierdan la honra; como hacedora de virgos deshace el entuerto que ella misma ha provocado. Para desactivar las reticencias de Pármeno, Celestina habla con él y le explica el oficio de Claudina, la madre fallecida del criado. Así habla de cómo aprendió de su maestra el arte de la hechicería:

«¡Oh qué graciosa era, oh qué desenvuelta, limpia, varonil! Tan sin pena ni temor se andaba a media noche de cimenterio en cimenterio, buscando aparejos para nuestro oficio, como de día. Ni dejaba cristianos ni moros ni judíos, cuyos enterramientos no visitaba. De día los acechaba, de noche los desenterraba. (...) Siete dientes quitó a un ahorcado con unas tenacicas de pelar cejas, mientras yo le descalcé los zapatos.» (De Rojas, 1984, pp. 155-6).

Para Celestina la verdadera sabia era Claudina. Pero no sólo ella le reconocía su buen hacer; además de partera, entre sus clientes se encontraban hombres de todas las edades y condición social. Caballeros, clérigos, casados, viejos y mozos utilizaron los saberes de Claudina, y como mujer sabia y bru- 
ja, necesitaba proveerse de dientes de hombre muerto para favorecer la potencia sexual de sus clientes. Así que este remedio, que estuvo avalado por autoridades médicas, se asoció con las mujeres al menos en un tratado judío de medicina femenina y en la célebre obra de Rojas. Sin embargo, hay una diferencia fundamental: cuando es utilizado por mujeres aparece ligado a un contexto mágico que, desde muy pronto, se vinculó con la práctica sanadora femenina. Aunque las causas de la impotencia estuvieran insertas en el sistema galénico, la posible falta de eficacia del tratamiento natural favoreció la aceptación de explicaciones mágicas y permitió la inclusión de remedios, utilizados también por las mujeres, en reputados libros de medicina universitaria.

Para los médicos la eventual incapacidad para identificar y administrar el compuesto correcto acorde con la teoría natural fue algo más que una mera posibilidad (Bos y Mensching, 2006, p. 262), pero cuando las mujeres utilizaban compuestos respaldados por las autoridades académicas su hacer aparece asociado a prácticas que se sitúan en los límites de lo prohibido. Sólo hubo una excepción: Trótula, que en la Edad Media fue fuente de autoridad médica en salud femenina. En el Liber de sinthomatibus mulierum, un texto del siglo XII que forma parte del conjunto de tratados que se le atribuían, se recomiendan como afrodisiacos, siguiendo a Plinio, el útero y la vagina de liebres y cerdos para los hombres y los testículos de dichos animales para las mujeres (McCartney, 1922, p.66; Plinio, 28.248).

«Si desea concebir un varón dale a su marido el útero y la vagina de una liebre. Disécalo y mezcla el polvo con vino y que lo beba. De igual forma haga la mujer con los testículos de una liebre, y al final de su periodo que yazca con su marido y un varón será concebido. Otra. Dale a la mujer el hígado y los testículos del único cerdo que haya nacido de una puerca, y sean secados y reducidos a polvo, y sea dado a beber al hombre que no es capaz de generar y éste generará, o bien a la mujer y ésta concebirá» (The Trotula, 2001, p. 95).

Este caso detalla cómo una mujer conocía estos remedios y prescribe su administración sobre el marido y su esposa. Los tratamientos usados por las mujeres, ya fueran empíricos o mágicos, como el ungüento de hormigas o el amuleto de diente de hombre muerto, fueron recogidos en libros de medicina universitaria. Pero las mujeres sabían, además, que el satirión era el elemento más apreciado por sus propiedades afrodisíacas por los médicos ilustrados. Ya me he referido a cómo la literatura bajomedieval atestigua el uso de alcahuetas para favorecer el encuentro sexual, y sin duda entre los clientes de estas mujeres también había clérigos. Este es el caso del Libro del Buen Amor, que narra las aventuras amorosas del arcipreste de Hita. Aunque el 
arcipreste también recurrió a hombres como mediadores, ninguno de ellos tuvo tanto éxito como Trotaconventos quien, entre otras muchas mujeres, recomienda la seducción de una monja. Según la alcahueta estas mujeres, a quienes en principio les estaba vedado el contacto carnal, estaban acostumbradas a tener amigos, a los que califica de «viciosos» para despejar cualquier duda sobre las relaciones que mantenían con ellas (Dean, 2008). Trotaconventos basa su consejo en más de diez años de convivencia con monjas y en el conocimiento de los compuestos que utilizaban en sus encuentros, recordando y destacando tres recetas, y en las tres el satirión es el elemento clave (Kane, 1933, p. 264):

\footnotetext{
«Muchos de letüarios les dan muchas vezes: diaçitrón, codonate, letüario de nuezes, otros de más quantía, de çahanorias rahezes; enbían unos e otros cada día a revezes.

Cominada alixandria, con el buen diagargante; el diaçitrón abatis, con el fino gengibrante; miel rosado, diaçimino, diantioso va delante; e la roseta novela, que deviera dezir ante.

Adragea e alfenique, con el estomaticón, e la garïofilata, con dïamargaritón; trïasándali muy fino, con dïasaturïon, que es para doñear, preçiado e noble don»». (Ruiz, 1992, 336-8)
}

$* * *$

La pericia y los conocimientos de las mujeres no se circunscribieron a los cuerpos femeninos, y aquellas que se arriesgaron a tratar a hombres fueron progresivamente deslegitimadas y marginadas, un proceso elaborado a distintos niveles: cultural, académico, ideológico y social (Agrimi, 2001, p. 493; Park, 1998, pp. 142-143; Cabré y Salmón, 1999). Las mujeres que trataron la impotencia masculina dieron un paso más; ellas no sólo estaban curando un cuerpo, lo que hacían era devolverles la masculinidad, es decir, la potencia sexual. Este conocimiento del cuerpo de los hombres sólo podía ser explicado porque ellas mismas, por brujería, habían provocado este mal. Pero el hecho fue que ni la identificación del origen de la impotencia ni su tratamiento estuvo exclusivamente en manos de hombres de iglesia o médicos. Si las mujeres podían ocasionar impotencia, también conocían remedios que terminaron por ser recogidos en textos médicos y utilizaron, además, tratamientos — como el 
satirión- que pertenecían al ámbito académico más erudito. Así pues, el conocimiento sobre las causas y terapias para la impotencia de los hombres no se quedó en la élite intelectual. Las mujeres, ya fueran sabias, brujas, viudas, casadas o monjas, fueron parte de la solución, y por ello fueron paulatinamente etiquetadas como la raíz del problema. Pero ni las fuentes académicas ni las eclesiásticas les reconocieron su saber, a pesar de que utilizaban remedios recomendados por ellos mismos. De hecho, recurrir a mujeres para solucionar la impotencia terminó por ser considerado un acto más peligroso que acudir a una bruja. Emplearan el método que emplearan, en sus manos siempre sería un uso ilícito, porque sólo era posible que supieran curar al hombre impotente si habían realizado una alianza expresa con el Demonio. Por ello Krämer y Sprenger sostienen que «acercarse a estas mujeres con ánimo de recuperar la salud se revela tanto más pernicioso cuanto que ellas actúan para deshonrar la fe más que aquellas que parecen realizar la cura exclusivamente mediante una alianza tácita con el diablo» (Krämer, 2004, p. 344).

El tratamiento de la impotencia no fue un conocimiento exclusivamente masculino, pero los hombres procuraron que para las mujeres fuera territorio vedado. Los hombres admitieron que las mujeres podían tener alguna autoridad sobre los cuerpos de otras mujeres y de los niños cuando el contacto físico era necesario, pero aceptar que ellas tenían competencia sobre el cuerpo de los hombres habría sido subvertir el orden establecido. Sin embargo, los tratamientos que utilizaron fueron, al fin y al cabo, los mismos.

\section{BIBLIOGRAFÍA}

Aecio de Amida (1950), The Gynaecology and Obstetrics of the VIth Century, (Ricci J.V. ed.trad), Filadelfia y Toronto, Blakiston, 1950.

Agrimi, J. (2001), "Le professioni mediche". En : AA. VV. Storia della Scienza, Roma, Istituto della Enciclopedia Italiana, pp. 485-494.

Amasuno, M. V. (1991), Medicina castellano-leonesa Bajomedieval, Valladolid, Universidad de Valladolid.

Aquino, Tomás de, (1961), Summa Teológica (Alonso, S., ed.), Madrid, Editorial Católica.

Austin, G. (2009), Shaping church law around the year 1000: the Decretum of Burchard of Worms, Farnham, Ashgate.

Avicena (1507), Liber Canonis, Venecia, [reimp. facsímil Hildesheim, Olms, G.1964].

Aviñón, J. de (1885), Sevillana Medicina, Sevilla, Rasco.

Bos, G. y Mensching, G. (2006), "A 15th Century medico-botanical synonym list (IberoRomance-Arabic) in Hebrew characters”, Panace@, VII (24): 261-268, [en línea] disponible en: http://tremedica.iwhome.com/panacea/IndiceGeneral/ n24 tribunahistoricabos.mensching.pdf. [consultado el 15/05/2011] 
FRÍGIDOS Y MALEFICIADOS. LAS MUJERES Y LOS REMEDIOS CONTRA LA IMPOTENCIA ...

Broedel, H.P. (2003), The Malleus Maleficarum and the Construction of Witchcraft. Theology and Popular Belief, Manchester y Nueva York, Manchester University Press.

Burnett, C. (1994), "The Chapter on the Spirits in the Pantegni of Constantine the African". En: Burnett, C. y Jacquart, D. (eds.), Constantine the African and 'Ali Ibn al'Abbas al-Magusi. The Pantegni and Related Texts, Leiden, Brill, pp. 99-120.

Caballero, C. (ed./trad.) (2003), El Libro de Amor de las Mujeres. Una compilación hebrea de saberes sobre el cuidado de la salud y la belleza del cuerpo femenino, Granada, Universidad de Granada.

Caballero, C. (2008a), “The care of women's health and beauty: an experience shared by medieval Jewish an Christian Women", Journal of Medieval History, 34, 146-163.

Caballero, C. (2008b), "Mujeres, cuerpos y literatura médica medieval en hebreo", Asclepio, lx (1): 37-62.

Cabré M. y Salmón, F. (1999), "Poder académico versus autoridad femenina: la facultad de París contra Jacoba Félicié (1322)", Dynamis, 19: 55-78.

Cabré, M. (2005), "Como una madre, como una hija: las mujeres y los cuidados de salud en la Baja Edad Media". En: Morant, I. (dir.) Historia de las Mujeres en España y América Latina, vol. 1, Madrid, Cátedra, pp. 637-657.

Cabré, M. (2008), "Women or Healers? Household Practices and the Categories of Health Care in Late Medieval Iberia", Bull. Hist. Med., 82: 18-51.

Cifuentes, L. (ed.) (2004), Libre D'Albumesar de Simples Medicines, (Arnaldi de Villanova Opera Medica Omnia XVII), Barcelona Universitat de Barcelona.

Cohn, N. (1980), Los demonios familiares de Europa, Madrid, Alianza.

Constantino el Africano (1983), Constantini Liber de Coitu. El tratado de Andrología de Constantino el Africano, (Montero, E. ed./trad.) Santiago de Compostela, Universidad de Santiago de Compostela.

Cotton, N. (1987), "Castrating (W)itches: Impotence and Magic in 'The Merry Wives of Windsor"', Shakespeare Quarterly, 38 (3): 320-326.

Dangler, J. (2001), Mediating Fictions: Literature, Women Healers, and the Go-Between in Medieval and Early Modern Iberia, Londres, Associated University Press.

De Rojas, F. (1984), La Celestina (Damián, B. M. ed.) Madrid, Cátedra.

Dean, T. (2008), "Fornicating with nuns in fifteenth-century Bologna", Journal of Medieval History, 34: 374-382.

Demaitre, L. (1980), Doctor Bernard Gordon: Professor and Practitioner, Toronto, PIMS.

Faraone, C.A. (1999), Ancient Greek Love Magic, Cambridge (Mass.), Harvard University Press.

Ferzoco, G. (2004), Il murale di Massa Marittima/The Massa Maritima Mural, Florencia, Consiglio Regionale della Toscana.

Forbes, T. R. (1971), "Verbal Charms in British Folk Medicine", Proceedings of the American Philosophical Society, 115(4): 293-316.

Gagnon, F. (2010), Le Corrector sive Medicus de Burchard de Worms (1000-1025), [tesis de M.A. inédita] Montreal, Université de Montreal. 
García Ballester, L. (1993), "On the origin of the «six non-natural things» in Galen". En: García Ballester, L. y Arrizabalaga, J., (eds.), Galen and Galenism, Aldershot, Ashgate, 2002, iv.

García Ballester, L. (2002), “La producción y circulación de obras médicas”. En: García Ballester (ed.), L., Historia de la Ciencia y de la Técnica en la corona de Castilla I. Edad Media, Valladolid, Junta de Castilla y León, pp. 709-788.

Gilbertus Anglicus (1510), Compendium Medicine, Lyon.

Giordano, O. (1983), Religiosidad popular en la Alta Edad Media, Madrid, Gredos.

Gómez García, (1997), "Libro de los olios, (López, M. ed.)”. En: Herrera, M ${ }^{\mathbf{a}}$ T y González $\mathrm{M}^{\mathrm{a}} \mathrm{E}$. (dirs.), Textos y concordancias del Corpus médico español, Madison, HSMS.

Gordonio, Bernardo (1993), Lilio de Medicina, (Dutton, B. y Sánchez, Ma N. eds.) Madrid, Arco/Libros,

Green, M. (1994), “The Re-creation of Pantegni, Practica, Book VIII”. En: Burnett, C. y Jacquart, D. (eds.), Constantine the African and 'Ali Ibn al-'Abbas al-Magusi. The Pantegni and Related Texts, Leiden, Brill, pp. 121-160.

Green, M. (ed./trad) 2001, The Trotula. A Medieval Compendium of Women's Medicine, Philadelphia, University of Pennsylvania.

Green, M. (2005a), “Constantine the African”. En: Glick, T., Livesey S. J. y Wallis, F. (eds.), Medieval Science, Technology, and Medicine. An Encyclopedia, Londres, Routledge, pp.145-147.

Green, M. (2005b), "Gilbertus Anglicus”. En: Glick, T., Livesey S. J. y Wallis, F. (eds.), Medieval Science, Technology, and Medicine. An Encyclopedia, Londres, Routledge, p. 196.

Green, M. (2008), Making Women's Medicine Masculine. The Rise of Male Authority in Pre-Modern Gynaecology, Oxford, Oxford University Press.

Harper, A (2011), "The Image of the Female Healer in Western Vernacular Literature of the Middle Ages", Social History of Medicine, 24(1): 108-124.

Heidecker, K.J. (2010), The Divorce of Lothar II. Christian Marriage and Political Power in the Carolingian World, Ithaca, Cornell University Press.

Herrera, Ma T (1996), Diccionario Español de Textos Médicos Antiguos, Madrid, Arco/Libros.

Hispano, P. (1973), Obras Médicas de Pedro Hispano, (Da Rocha, Mª H. ed/trad.) Coimbra, Acta Vniversitatis Conimbrigensis

Horden, P. (2011), "What's wrong with Early Medieval Medicine", Social History of Medicine, 24(1): 5-25.

Ibn al-Jazzār (1997), On Sexual Diseases and Their Treatment. A Critical Edition of Zād al-musāfir we-qūt al-hādir, (Bos, G. ed./trad.) Londres y Nueva York, Kegan Paul International

Isidoro de Sevilla, (1982), Etimologías (Oroz, J. y Marcos, M.A. eds.) Madrid, B.A.C.

Jacquart, D. (1987), "Medical Explanation of Sexual Behavior in the Middle Ages", Homo Carnalis, Acta XIV: 1-21.

Jennett, S. (1963), Journal of a Younger Brother, The Life of Thomas Platter as a medical student in Montpellier at the close of the Sixteenth Century, Londres, F. Muller.

Jones, K. y Zell, M. (2005), "The divels special instruments': women and witcheraft before the 'great witch-hunt"', Social History, 30(1): 45-63. 
FRÍGIDOS Y MALEFICIADOS. LAS MUJERES Y LOS REMEDIOS CONTRA LA IMPOTENCIA ...

Kane, E. K. (1933), "The Electuaries of the Archpriest of Hita", Modern Philology, 30(3): 263-266.

Kieckhefer, R. (1976), European Witch Trials. Their Foundations in Popular and Learned Culture, 1300-1500, Londres, Routledge.

Kieckhefer, R. (1994), "The Specific Rationality of Medieval Magic", American Historical Review, Junio, 813-836.

Krämer, H. (2004), Malleus maleficarum (Jiménez, M. ed/trad), Valladolid, Maxtor.

Laguna, A. (1733), Pedacio Dioscorides Anazarbeo, Madrid, Alfonso Balbas.

Longenbach, E. M., (2008), A Fountain Bewitched: Gender, Sin, and Propaganda in the Massa Marittima Mural (M.A. thesis), University of North Carolina, Chapel Hill.

Macdougall, S. C. (2000), "The surgeon and the saints: Henri de Mondeville on the divine healing", Journal of Medieval History, 26 (3): 253-267.

Mackinney, L. (1943), “An Unpublished Treatise on Medicine and Magic from the Age of Charlemagne", Speculum, 18(6): 494-496.

Martínez, J. y McVaugh, M.R. (eds.) (2004), Translatio libri Albuzale de medicinis simplicibus, Barcelona, Universitat de Barcelona.

McCartney, E. S. (1922), "Sex Determination and Sex Control in Antiquity", American Journal of Philology, 43(1): 62-70.

McVaugh, M.R. y Ferre, L. (2000), “The 'Tabula Antidotarii' of Armengaud Blaise and its Hebrew Translations", Transactions of the American Philosophical Society, New Series, 90 (6): 102-104.

Metrodora, (1953), Sulla malattie delle donne e il recerrario di cosmetica e terapia, (Del Guerra, G. ed./trad.) Milan, Santoriana.

Migne J.P. (1993-5), Patrologia Latina Database, Alexandria (Virginia), Chadwick Healey [5 CR-ROM].

Montero, E. (ed./trad.) (1993), Tractatus de sterilitate, Valladolid, Universidad de Valladolid.

Montero, E. (1999), "El Lilivm Medicinae de Bernardo de Gordon y la literatura medieval sobre la esterilidad", En: Aldama, A. Ma. et al. (eds.), La Filología Latina Hoy, Madrid, SEL, pp. 709-715.

Montero, E. (2010), "Remedia contra maleficia: origen y formación”, Interclassica, 10: 133-160.

Moral, P. (2007), "Magic or Science? What «Old Women Lapidaries» knew in the age of Celestina", La Corónica, 36(1):203-35.

Moral, P. (2010), "Espacios femeninos. El proceso de legitimación masculina del saber y las prácticas sanitarias femeninas”. En: C. González y F. Martínez (eds.), La transformación de la Enfermería. Nuevas miradas para la Historia, Granada, Comares, pp. 75-93.

Murray, J. (1998), "Individualism and Consensual Marriage: Some Evidence from Medieval England". En: Rousseau, C.M y Rosenthal, J.T. (eds.), Women, Marriage, and Family in Medieval Christendom. Essays in Memory of Michael M. Sheehan, Kalamazoo, Michigan, pp. 121-151.

Olsan, L.T. (2003), "Charms and Prayers in medieval Theory and Practice", Social History of Medicine, 16(3): 343-366. 
Page, S., (2000), Magic at St. Augustine's, Canterbury, in the Late Middle Ages [tesis doctoral inédita], Londres, Warburg Institute.

Park, K. (1998), "Medicine and Magic: The Healing arts". En: Brown J.C. y Davis R.C. (eds.), Gender and Society in Renaissance Italy, Londres y Nueva York, Longman, pp. 129-149.

Payer, P. J. (2009), Sex and the New Medieval Literature of Confession, 1150-1300, Toronto, Pims.

Pliny, (1963), Natural History (W.H.S. Jones ed.), Londres y Cambridge (Mass.), Harvard University Press.

Reynolds, P. L. (1994), Marriage in the Western Church. The Christianization of Marriage During the Patristic and Early Medieval Periods, Leiden, Brill.

Riddle, J.M. (2010), Goddesses, Elixirs, and Witches. Plants and Sexuality throughout Human History, Nueva York, Palgrave-Macmillan.

Rider, C (2011), "Medical Magic and the Church in Thirteenth-Century England", Social History of Medicine, 24 (1): 92-107.

Rider, C. (2006), Magic and Impotence in the Middle Ages, Oxford, Oxford University Press.

Ruiz, J. (1992), Libro del Buen Amor (Blecua, A. ed.) Madrid, Cátedra.

Scot, R. (1651), The Discovery of Witchcraft, [Londres], R.[ichard] C.[otes].

Sigerist, H. E. (1943), "Impotence as a Result of Witchcraft". En: Essays in Biology, in Honor of Herbert M. Evans, Los Ángeles, University of California Press, pp. 541546.

Smith, M. (2002), "The Flying Phallus and the Laughing Inquisitor: Penis Theft in the 'Malleus Maleficarum"'. Journal of Folklore Research, 39(1): 85-117.

Smith, M. (2009), "Reconsidering the 'Obscene': The Massa Marittima Mural", Shift: Graduate Journal of Visual and Material Culture, 2: [en línea] disponible en: http://www.shiftjournal.org/articles/2009/Smith.pdf. [consultado el 15/05/2011]

Stannard, J. (1964), “A Fifteenth-Century Botanical Glossary (Huntington Library MS HM 64)", Isis, 55(181): 353-367,

Stannard, J. (1979), "Identification of the Plants described by Albertus Magnus, De vegetabilibus, lib.vi”, Res Publica Litterarum 2: 281-318.

Stannard, J. (1982), "Medicinal Plants and Folk Remedies in Pliny, Historia Naturalis", History and Philosophy of the Life Sciences, 4(1): 3-23.

Stephens, W. (1998), "Witches who Steal Penises: Impotence and Illusion in Malleus Maleficarum", Journal of Medieval and Early Modern Studies, 28 (3): 495-529.

Stephens, W. (2003), Demon Lovers. Witchcraft, Sex, and the Crisis of Belief, Chicago, The University of Chicago Press.

Zurrón, I. (ed.) (1997), “Libro de recetas”. En: Herrera, Ma T. y González, Ma E. (dirs.), Textos y concordancias del Corpus médico español, Madison, Hsms.

Recibido: 26 de enero de 2011

Aceptado: 28 de noviembre de 2012 